\title{
Cosmología y naturaleza mbya-guaraní
}

\author{
Marilyn Cebolla Badie. 2016. Cosmología y naturaleza mbya-guaraní. Editorial Biblos, año 2016, 312 \\ PÁGINAS.
}

\section{( Hugo Lavazza}

Universidad de Buenos Aires. Facultad de Filosofía y Letras, Instituto de Ciencias Antropológicas. Buenos Aires, Argentina Instituto Nacional de Medicina Tropical (INMeT). Puerto Iguazú, Misiones, Argentina

CORREO ELECTRÓNICO: VLAVAZZA@HOTMAIL.COM

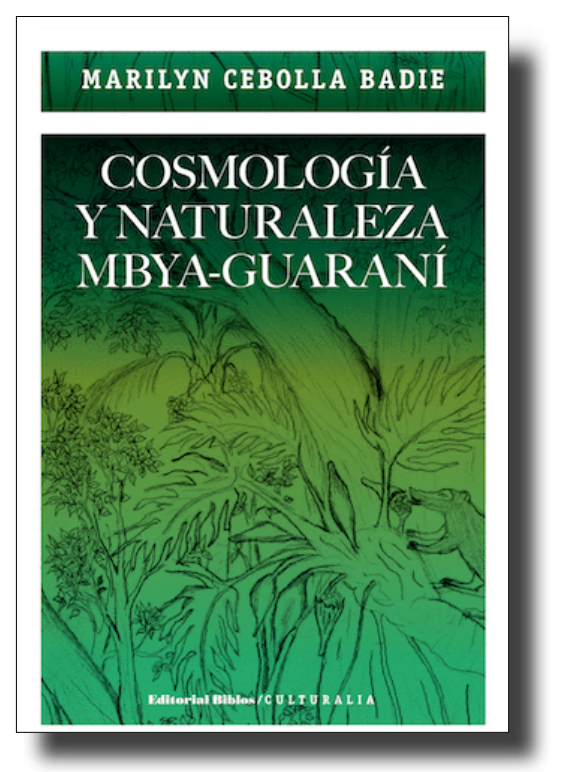

La etnografía de Marilyn Cebolla Badie está fuertemente sustentada desde la teoría por el perspectivismo de Eduardo Viveiros de Castro (2004) y por las ontologías de Philippe Descola (2015), de modo predominante. Se trata de una línea teórica que trabaja con "la naturaleza" y el sistema social asociado con cierta concepción de esta, pero básicamente entendida como parte de un mismo conjunto ecológico, y es lo que la autora pretende manifestar en su libro.

El texto se divide en tres partes: la primera se dedica a ubicar en situación etnohistórica a las poblaciones mbya, y está dividida a la vez en tres secciones: la historia de la región tomando como eje a los guaraníes; cómo está compuesta la etnia; su sistema cosmológico y cómo se relacionan con el entorno. La segunda parte retoma la ontología mbya para tratar a los animales y seres extrahumanos. En la tercera parte se relacionan los capítulos precedentes con la subsistencia teniendo en cuenta las relaciones que los mbya establecen con los animales mamíferos cazables. La autora lo titula "La predación y el consumo".

Las aldeas mencionadas por la autora son Takuapi e Ita Poty, Jejy, Yryapy y Fortín Mbororé, de las cuales describe su ubicación geográfica, características distintivas y algunas dificultades metodológicas con las que se encontró a lo largo de su trabajo. Por establecer un ejemplo, menciona la proporción entre personas de sexo femenino y masculino entre las cuales consiguió entrevistas. En este punto, señala que la mayoría fueron de sexo masculino (aunque tuvo acceso a testimonios de mujeres) debido a la dificultad de que las mujeres hablen de su condición como mbya (p. 36).

En la primera parte de su libro, Cebolla Badie se explaya acerca de la organización social y del territorio que ocupaban los mbya y el motivo de las lógicas de los traslados o migraciones actuales. Para esclarecer este punto se refiere en primer lugar la dinámica social de las aldeas tomando en cuenta el frente de expansión agrícola, ya que "se fue produciendo progresivamente el contacto obligado y cada vez más permanente de los mbya con la sociedad blanca en general de Misiones" (p. 53); circunstancia esta que hizo variar en alguna medida el modo de organización de los mbya. La autora menciona el caso de un anciano que quería trasladarse y tenía en mente la conformación del antiguo Tekoa, unidad geográfico-social mayor a la aldea, donde se encuentran varios poblados de blancos. En este sentido, la frecuencia de los desplazamientos ha disminuido, por la forma de reducción que tienen las aldeas: a pesar de la configuración aldeana, ellos continúan moviéndose para ver a sus familiares, para luego regresar, sin abandonar las coordenadas de la población significada por el Tekoa. Sin embargo, también, la movilidad responde a encontrar un sitio que cuente con monte para desarrollar su cosmología, su mundo de vida cazador y desenvolver la pericia hortícola de la cultura mbya. 
Esto es lo que Cebolla Badie describe en las secciones subsiguientes. Al respecto, señala que se valdrá de una sección relativa a la religión para poder complementar con la organización social y pasar al tema de la extrahumanidad de los animales y sus consecuencias para la predación y la caza.

Un aspecto significativo de dicha sección es lo que la autora afirma: "La religiosidad impregna la vida cotidiana de los mbya, así los puntos cardinales, el amanecer y el atardecer están relacionados con ámbitos donde moran los dioses" (p. 93). La pareja divina que regula la vida cotidiana y extraordinaria en los rituales está conformada por Karai Ru Ete, Karai Chy Ete (Ru Ete significa Padre Verdadero, y Chy Ete Madre Verdadera). Para reafirmar esto, explica que, durante la noche, las personas hablan sobre el comportamiento de las deidades, ya que "Los dioses observan a los seres humanos y especialmente a los opygua o líderes religiosos, utilizando el jechara, reflejo o espejo del sol... Esta sería la razón del día y la noche para los mbya" (p. 94).

En su organización, el texto denota que a pesar de la presencia "blanca", existen espacios perdurables en los que los mbya-guaraní transcurren en armonía con el medio ambiente y con ello verifica, de este modo, la íntima relación en la que concurren con la naturaleza. Considerando esto es que debemos pensar las siguientes secciones del texto; a partir de esa tensión entre la organización social y la religiosidad en el contexto de un determinado ambiente, el monte, la selva.

La autora expresa que "Si tomamos Ka'aguyo selva en el sentido de naturaleza para los mbya podríamos decir que ésta se define como espacio que no es humano" (p. 129). Y lo dice después de observar que el espacio de la naturaleza es "lo que no es la aldea o lo que no es aldea ni huerto" (p. 129). Por ello, todos los animales con que los mbya se relacionan tienen esta característica de lo que está afuera de la aldea. Dada esta situación, caen en el ámbito de la conjunción ecológica: los animales y los vegetales poseen dueños de los lugares según el sitio donde se encuentren personificados. La autora menciona una nutrida cantidad de animales sujetos a un régimen de deixis cosmológica. Los que Cebolla Badie destaca como los más importantes son: el chivi (el jaguar) es no comestible pero cosmológicamente peligroso; ypo (habitantes del agua), como la nutria; el kochi (pecarí), considerado el animal doméstico de los dioses. Este tratamiento dado a los animales del entorno se obtienen mediante la rogativa a los dueños ya que son entidades personificadas, pero no humanas, está acorde con el modo de la predación y el consumo. Por ese motivo existen connotaciones morales para no cazar en exceso o maltratar a la presa (p. 278).

El libro se encuentra estructurado alrededor de estos temas que han sido resumidos, pero que el lector los encontrará expandidos en el texto. Se trata en definitiva de una etnografía minuciosa y actualizada sobre los mbya.

\section{Referencias bibliográficas}

»Descola, Phillipe. 2015. Más allá de la naturaleza y la cultura. Buenos Aires: Amorrortu.

"Viveiros de Castro, Eduardo. 2011. A inconstância da Alma Selvagem e otros ensaios de antropología. San Pablo: Cosac y Naify. 